Review

\title{
Depression in Children and Adolescents with Autism Spectrum Disorder
}

\author{
Melissa DeFilippis \\ Department of Psychiatry, University of Texas Medical Branch, Galveston, TX 77555, USA; msdefili@utmb.edu
}

Received: 25 July 2018; Accepted: 16 August 2018; Published: 21 August 2018

\begin{abstract}
Autism spectrum disorder (ASD) has a high rate of psychiatric comorbidity. The prevalence of comorbid depression seems to correlate with higher functioning forms of ASD and increasing age. Adolescence is a time when youth struggle with identity and interpersonal relationships, and a diagnosis of ASD further complicates this process. Adolescents with ASD may be more aware of the social communication deficits that come with the diagnosis than children with ASD, and it is theorized that higher functioning adolescents may experience this more acutely. While this may be true, the lack of reliable rating and diagnostic scales for depression in individuals with ASD makes it difficult to accurately measure rates of depression among individuals with more severe verbal deficits. While some research has focused on the prevalence of comorbid depression in children and adolescents with ASD and on the associated risk factors, there is very little evidence guiding treatment, including no empirical studies on psychopharmacology for depression in this population. Available evidence exists only in psychosocial approaches to treatment at this time and is mostly limited to adult studies. Current evidence will be presented in this review, including prevalence rates of depression in youth with ASD, various risk and protective factors, the use of diagnostic rating scales, and treatment studies. The lack of evidence supporting various treatment approaches will be highlighted, including challenges specific to the treatment of depression in ASD, which are not addressed in the current treatment studies in typically developing youth with depression.
\end{abstract}

Keywords: autism spectrum disorder; depression; adolescents; prevalence; treatment

\section{Introduction}

Autism is a diagnosis that includes social communication deficits and restricted and repetitive behavior, interests, or activities, which are severe enough to significantly impair functioning [1]. The prevalence of autism spectrum disorder (ASD) has increased significantly over the past few decades, now affecting 1 in 59 children in the United States, based on recent Centers for Disease Control data [2]. ASD also frequently includes associated behavioral symptoms and comorbid psychiatric diagnoses, which can be as impairing as the core symptoms in some cases. It can be difficult to distinguish associated symptoms of ASD from comorbid psychiatric diagnoses (repetitive behaviors in ASD may be very similar to compulsions seen with obsessive-compulsive disorder, for example), making it hard to measure true comorbidity in youth with ASD. There is a relative lack in validated instruments for measuring comorbid psychiatric illnesses in the ASD population; therefore, it is no surprise that prevalence estimates of depression vary widely, from $2 \%$ to $30 \%$ [3]. Correctly identifying comorbid diagnoses in children and adolescents with ASD is important in guiding clinicians toward more appropriate and targeted treatment for these symptoms.

Depression is a fairly common diagnosis in youth, affecting about $12 \%$ of adolescents in the general population [4]. Most youth with one episode of depression will experience a recurrence of their symptoms at some point in adolescence or young adulthood [5]. Depression can include isolation and interpersonal struggles, which may also be present in ASD, and there is always a concern about 
suicidality in youth with depression. Individuals with ASD and depression may experience an increase in obsessions and rituals or, by contrast, a complete loss of interest in former preoccupations. Agitation, stereotypical behaviors, and self-injury may increase with depression. In patients with significant deficits in verbal skills, clinicians may need to rely more on vegetative signs, including decreased adaptive functioning skills and significant appetite and sleep disturbances compared to baseline [6]. Reviewing research on the prevalence rates and risk factors of depression in youth with ASD is important to help clinicians more accurately diagnose depression in this population and provide appropriate interventions. More research is needed examining efficacy and safety of treatment of depression in youth with ASD as current evidence is lacking in this area, and most treatment decisions are extrapolated from research in depressed youth with typical development [7].

\section{Prevalence}

Several studies examining prevalence of comorbid psychiatric symptoms and diagnoses in ASD have shown increased rates of both when compared to the general population, though the rates vary between studies. Accurately measuring the presence of depressive disorders in individuals with ASD is further complicated by the lack of appropriate rating and diagnostic scales for this population. In higher functioning youth with ASD, rating scales used in youth with typical development may be considered, but questions focused on more subjective symptoms, such as guilt and worthlessness, may be difficult for individuals with ASD and their parents to answer correctly [8]. In lower functioning individuals with ASD, scales developed for use in individuals with intellectual disability may be considered, such as the Reiss Scale [9] or the Disability Assessment Schedule [10]. The Autism Comorbidity Interview-Present and Lifetime version (ACI-PL) may be a more reliable measure in youth with ASD [11]. This scale includes questions about increased agitation, self-injury, and temper outbursts as well as asking about baseline functioning and measuring change from baseline. It also seeks to distinguish impairment from comorbid psychiatric diagnoses from impairment from the core ASD symptoms.

A population-based study examined the prevalence of psychiatric disorders in 112 children and adolescents (aged 10 to 14) with ASD [12]. About 70\% of the youth had at least one comorbid disorder and $41 \%$ had two or more comorbid disorders based on parent interview using the Child and Adolescent Psychiatric Assessment (CAPA) [13]. The three-month point prevalence for depressive symptoms in this sample was $1.4 \%$. A study of comorbid psychiatric diagnoses in ASD used the Autism Interactive Network database and included 4343 children and adolescents with ASD, $11 \%$ of which had a parent-reported history of comorbid depression [14].

A study examined the prevalence of comorbid psychiatric disorders in 177 youth with ASD, aged 3 to 18 years [15]. Using the Child Behavior Checklist, parents reported a 26\% comorbidity rate of significant affective symptoms in their children [16,17]. Teacher ratings were lower, with only $6.2 \%$ rated at clinically significant ranges for affective symptoms, suggesting environmental effects on symptom expression. Other studies have shown different trends in multi-informant reports. One study examining comorbid psychiatric symptoms in 260 adolescents aged 11 to 17 years (including 43 with a diagnosis of Asperger syndrome or autism) showed higher rates of depressive and anxiety symptoms in the youth with ASD (26\% in ASD youth compared to $12 \%$ in control group) [18]. Unlike the Kanne study, this one showed higher teacher-reported ratings of symptoms when compared to parental reports.

A validity/reliability study of the Autism Comorbidity Interview-Present and Lifetime version (a modification of the Kiddie Schedule for Affective Disorders and Schizophrenia-K-SADS) showed high rates of comorbid psychiatric disorders in a sample of 109 youth with ASD (aged 5 to 17 years) $[12,19,20]$. In this sample, $10 \%$ met diagnostic criteria for major depressive disorder, and $24 \%$ had subsyndromal depressive symptoms. A small study of 33 adolescents with Asperger syndrome (aged 12 to 17 years) showed 9\% scoring in the significant range for depression on the Children's 
Depression Inventory (CDI); however, $70 \%$ of the study participants were already being treated with antidepressants [21,22]. Prevalence studies of depression in youth with ASD are listed in Table 1.

Table 1. Prevalence Studies of Depression in Youth with autism spectrum disorder (ASD).

\begin{tabular}{ccccc}
\hline Study/Year & $\begin{array}{c}\text { Number of } \\
\text { Participants }\end{array}$ & Prevalence of Depression & Scale Used & Comments \\
\hline Simonoff et al., 2008 & 112 & 3 month point prevalence $=1.4 \%$ & CAPA & $\begin{array}{c}\text { Autism Interactive } \\
\text { Network Database }\end{array}$ \\
\hline Rosenberg et al., 2011 & 4343 & $11 \%$ & $\begin{array}{c}\text { Parent-reported community } \\
\text { diagnoses of depression }\end{array}$ & CBCL \\
\hline Kanne et al., 2009 & 177 & $\begin{array}{c}26 \% \text { - parent-rated } \\
6 \% \text {-teacher-rated }\end{array}$ & CBCL & $\begin{array}{c}\text { Scale designed specifically for } \\
\text { measuring psychiatric } \\
\text { comorbidity in ASD }\end{array}$ \\
\hline Hurtig et al., 2009 & 260 & $26 \%$ (anxiety or depressive symptoms) & ACI-PL & 10\%-MDD \\
\hline Leyfer et al., 2006 & 109 & $24 \%$-subsyndromal depressive symptoms & CDI & $\begin{array}{c}70 \% \text { of participants already on } \\
\text { antidepressant medication }\end{array}$ \\
\hline Barnhill et al., 2001 & 33 & $9 \%$ &
\end{tabular}

A number of studies have compared prevalence rates of psychiatric disorders between youth with ASD and either the general population or typically developing youth. A large population-based longitudinal study included 6091 adolescents with and without ASD and examined the association with depression over eight years [23]. Using the Short Mood and Feelings Questionnaire (SMFQ) as the measure for depressive symptoms, adolescents with ASD had higher average scores when compared to the general population at age 10 years, and scores remained elevated in an upward trajectory until age 18 [24]. Depression at age 18 was associated with social communication impairments and bullying. Youth with ASD showed higher rates of depressive and anxiety symptoms than youth in the general population as measured by the Revised Ontario Child Health Study (OCHS-R), a revision of the CBCL $[25,26]$. This study included 59 children and adolescents with ASD and 1751 children from the community (general population control), aged 9 to 14 years. In the ASD group, about $17 \%$ scored in the significant rage on depression items compared to $3 \%$ in the general population.

A study of 70 adolescents, with mean age of 14 , compared rates of depression in youth with ASD $(n=35)$ and youth without ASD $(n=35)$ [27]. Depressive symptoms were measured using the Centre for Epidemiological Studies Depression Scale-Children's Version (CES-DC), and the results showed significantly higher rates of depressive symptoms in the ASD group versus the comparison group (66\% and $40 \%$, respectively) [28]. One study compared rates of depressive symptoms between 30 youth with ASD, 30 typically developing (TD) youth with major depressive disorder (MDD), and 35 typically developing youth without MDD, aged 7 to 17 years [29]. Depressive symptoms were assessed using the CDI and the Children's Depression Rating Scale-Revised (CDRS-R) [30]. The ASD group showed significantly higher rates of depressive symptoms when compared to the TD group and similar rates of depressive symptoms as the MDD group. Depressive symptoms were associated with poorer global functioning in the ASD group.

Comparisons between ASD and other disorders have also shown differences in rates of comorbid psychiatric diagnoses and symptoms. A comparison study examined the difference in psychopathology between children and adolescents with autism and intellectual disability (ID) [31]. The ASD group had participants both with and without ID, but the ID group did not include participants with ASD. This study included 962 youth, aged 4 to 18 years, and used parent-reported symptoms on the Developmental Behavior Checklist (DBC-P) [32,33]. There were significantly higher levels of psychopathology, including depressive symptoms, in the ASD group when compared to the ID group. Higher scores on the depression scales were associated with increased age and higher intelligence quotient (IQ). Comorbid depression is commonly seen with other disorders, including disruptive behavior disorders. Youth with ASD were shown to have similar rates of depressive symptoms as youth with conduct disorder (CD) in a small study of 40 adolescents, aged 11 to 19 years [34]. 


\section{Risk and Protective Factors}

Youth with ASD and comorbid depression have a higher incidence of family history of depression when compared to youth with ASD without comorbid depression, similar to research in depressed youth without ASD [35]. Additionally, rates of depression are higher in first degree relatives of individuals with ASD when compared to first degree relatives of individuals with Down syndrome, when controlling for stress associated with raising a child with ASD [36]. Environmental stressors also play a role in the risk of depression in individuals with ASD, just as they do in typically developing youth. Youth with ASD have reported increased negative life events 12 months prior to the onset of depression when compared to controls [37]

Evidence shows risk of depression increases with increasing IQ and higher levels of functioning as well as with increasing age in youth with ASD. A large study examined prevalence and risk factors of anxiety and depression in 627 youth with autism, ages 1 to 17 years [38]; IQ ranged from 16 to 146. The parent-rated Pediatric Behavior Scale (PBS) was used to measure rates of anxiety and depressive symptoms in the study participants [39]. Prevalence of depressive symptoms ranged from $22 \%$ to $72 \%$ across the age groups, with the highest rates seen in the older groups. Along with age, the biggest predictors for depression in this study included increased verbal IQ and increased maternal-rated ASD symptom severity, with the latter being the single best predictor of both anxiety and depression.

A study of 1390 children and adolescents, including 350 with ASD, examined prevalence rates of several symptoms in different groups of children and adolescents, including controls in the general population and clinically referred youth with various psychiatric diagnoses, aged 6 to 16 years [40]. With regards to ASD and depression, the study showed higher rates of depressive symptoms (54\%) among youth with ASD and IQ $\geq 80$ when compared to youth with ASD and IQ $<80$ as measured by the PBS [39]. The study also found that youth with ASD and depression had lower rates of suicidal ideation and suicide attempts when compared to typically developing youth with depression. Though depression risk increases with age, evidence shows younger children with ASD are still at risk of developing symptoms. A study of 101 children with ASD, aged 4 to 9 years, showed a prevalence of depression that ranged from $6 \%$ (IQ < 70) to $19 \%$ (IQ $\geq 70$ ) [41]. Though higher IQ was associated with a higher prevalence of depressive symptoms, this finding did not reach statistical significance in this study. Anxiety symptoms, however, were significantly associated with a higher IQ.

A study examined the effect of different coping strategies and level of social functioning on depression in 120 male subjects (mean age 11), including 63 youth with ASD (IQ $\geq 80$ ) and 57 youth with typical development [42]. When compared to the youth with typical development, those in the ASD group who reported using avoidant strategies to manage stressful situations reported fewer symptoms of depression on the CDI, suggesting a possible adaptive coping strategy in this group. Poor social functioning was associated with increased symptoms of depression [22].

The trajectory of depressive symptoms in youth with ASD has been studied with some mixed results; however, all evidence supports higher rates of depression than in the general population that remains into adulthood. One study showed improvements of depressive symptoms in youth with ASD as they aged [43]. Other clinical trials, however, have shown symptoms of depression either remaining elevated at similar rates or at increasing rates in older adolescents and young adults with ASD $[23,44]$. Social communication deficits have been shown to be associated with an increased risk of self-harm and suicidal ideation in youth [45]. This risk appears to be independent of an ASD diagnosis, suggesting typically developing youth with social communication deficits are also at an increased risk of suicidal thoughts and behaviors. Depression in early adolescence appears to contribute somewhat to this risk, which highlights the importance of early interventions for depression in children and adolescents. More research is needed to better understand risk factors associated with suicidal thoughts and behaviors in youth with ASD. 


\section{Treatment}

Treatment for depression in youth with ASD tends to be guided by evidence from studies of typically developing children and adolescents with depression. There is not much evidence to help clinicians make treatment decisions, and there are no randomized, placebo-controlled trials examining efficacy of antidepressants for the treatment of depression in youth with ASD [46]. Antidepressant treatment studies in youth with ASD have focused almost exclusively on the core symptoms of autism, specifically repetitive behaviors. Randomized controlled trials have failed to show efficacy of selective serotonin reuptake inhibitors (SSRIs) for repetitive behaviors in youth with autism, and side effects have been a concern in these studies (specifically, serotonergic activation effects) [47,48]. A small, 10-week, open-label study of escitalopram in 28 children and adolescents with ASD (aged 6 to 17 years) showed significant improvement in symptoms of irritability but did not measure depressive symptoms specifically [49]. The youth in the study experienced dose-related adverse effects of irritability and hyperactivity, and a quarter could not tolerate doses above $10 \mathrm{mg}$. Responders tended to do so at lower doses of escitalopram.

The lack of evidence supporting the use of SSRIs in children and adolescents with ASD is concerning as these are the most commonly prescribed psychotropic medications in individuals with ASD [50,51]. A study examining medication use in 286 adolescents and adults with ASD (mean age 21) showed $33 \%$ of the study participants were prescribed antidepressants, rising to $43 \%$ by the end of the four-year study [52]. This was the most common psychotropic prescribed to the individuals in the study. A Cochrane Review concluded that antidepressants should only be used on a case-by-case basis for depression or obsessive-compulsive disorder in children with autism, but the evidence does not really support its use, and there is significant evidence showing potential harm in this patient population [53]. Clinicians should use their clinical judgment when considering antidepressants for children and adolescents with ASD. If the decision to treat with antidepressants is made, then clinicians should choose low doses to start, titrate slowly, and carefully monitor for response and adverse effects.

Much of the evidence pertaining to psychosocial interventions, such as cognitive behavior therapy, is focused on treating either core symptoms of ASD, associated behavioral symptoms, or anxiety [54]. A few studies have examined the efficacy of psychosocial interventions for depression in individuals with ASD; however, most of these have been adult studies. One study examined the efficacy of group cognitive behavioral therapy on symptoms of anxiety, stress, and depression in 32 adolescents and young adults with ASD (aged 15 to 25 years) [55]. When compared to the wait list control, individuals in the CBT group with symptoms of depression pretreatment showed significant improvement in their depressive symptoms, as measured by the Depression Anxiety Stress Scales (DASS) [56]. Studies in adults with ASD have shown mindfulness-based therapy and social and vocational skills training to be effective for symptoms of depression, but neither intervention has been studied as a treatment for depressive symptoms in children or adolescents with ASD [57,58]. Evidence is still lacking in this area but psychosocial interventions, such as cognitive behavior therapy, should be considered as treatment options for youth with ASD and comorbid depression.

\section{Conclusions}

Depression is a fairly common comorbid diagnosis in children and adolescents with autism. It may be harder to recognize in this patient population due to communication deficits, and symptoms of depression may compound the interpersonal difficulties that youth with ASD already experience. Accurate diagnosis may be difficult, especially in children and adolescents with limited verbal skills. Reliance on parental-report and change from baseline behaviors is very important in these cases. Current diagnostic scales may not be ideal for diagnosing depression in youth with ASD, and scales developed specifically for youth with ASD, such as the ACI-PL, may be more reliable in this patient population. Research examining the efficacy of various treatments for depression in individuals with ASD is very limited, especially in children and adolescents, and there are currently no randomized controlled trials examining the safety and efficacy of treatments for depression in this population. 
Considering the rates of depression seen in youth with ASD are higher than those observed in typically developing youth, the lack of guidance for clinicians treating these patients is concerning. Additionally, evidence suggests youth with ASD are at a higher risk of developing adverse effects with antidepressant medications, and traditional psychosocial interventions need more study to determine whether they are as effective in this population as in typically developing youth with depression. Antidepressants continue to be the most commonly prescribed psychotropic medications for patients with ASD despite concerns about side effects and lack of evidence supporting their use in this patient population. Future research should focus on symptom expression in depressed youth with ASD and how it may differ from typically developing youth. It should also focus on establishing appropriate assessments for these symptoms and safe and effective treatments for depression in this patient population.

Funding: This research received no external funding.

Conflicts of Interest: The author declares no conflict of interest.

\section{References}

1. American Psychiatric Association. Diagnostic and Statistical Manual of Mental Disorders, 5th ed.; American Psychiatric Publishing: Arlington, VA, USA, 2013; ISBN 978-0-89042-554-1.

2. Baio, J.; Wiggins, L.; Christensen, D.L.; Maenner, M.J.; Daniels, J.; Warren, Z.; Kurzius-Spencer, M.; Zahorodny, W.; Robinson Rosenberg, C.; White, T.; et al. Prevalence of autism spectrum disorder among children aged 8 years-Autism and developmental disabilities monitoring network, 11 sites, United States, 2014. MMWR Surveill. Summ. 2018, 67, 1-23. [CrossRef] [PubMed]

3. Matson, J.L.; Nebel-Schwalm, M.S. Comorbid psychopathology with autism spectrum disorder in children: An overview. Res Dev Disabil. 2007, 28, 341-352. [CrossRef] [PubMed]

4. Merikangas, K.R.; He, J.; Burstein, M.; Swanson, S.A.; Avenevoli, S.; Cui, L.; Benjet, C.; Georgiades, K.; Swendsen, J. Lifetime prevalence of mental disorders in US adolescents: Results from the National Comorbidity Study-Adolescent Supplement (NCS-A). J. Am. Acad. Child Adolesc. Psychiatry 2010, 49, 980-989. [CrossRef] [PubMed]

5. Melvin, G.A.; Dudley, A.L.; Gordon, M.S.; Ford, S.; Taffe, J.; Tonge, B.J. What happens to depressed adolescents? A follow-up study into early adulthood. J. Affect. Disord. 2013, 151, 298-305. [CrossRef] [PubMed]

6. Ghaziuddin, M.; Ghaziuddin, N.; Greden, J. Depression in persons with autism: Implications for research and clinical care. J. Autism Dev. Disord. 2002, 32, 299-306. [CrossRef] [PubMed]

7. Chandrasekhar, T.; Sikich, L. Challenges in the diagnoses and treatment of depression in autism spectrum disorders across the lifespan. Dialogues Clin. Neurosci. 2015, 17, 219-227. [PubMed]

8. Stewart, M.E.; Barnard, L.; Pearson, J.; Hasan, R.; O'Brien, G. Presentation of depression in autism and Asperger syndrome. Autism 2006, 10, 103-116. [CrossRef] [PubMed]

9. Reiss, S. Reiss Scales for Children's Dual Diagnosis: Mental Retardation and Psychopathology; International Diagnostic Systems: Worthington, OH, USA, 1990.

10. Holmes, N.; Shah, A.; Wing, L. The disability assessment schedule: A brief screening device for use with the mentally retarded. Psychol. Med. 1982, 12, 879-890. [CrossRef] [PubMed]

11. Leyfer, O.T.; Folstein, S.E.; Bacalman, S.; Davis, N.O.; Dinh, E.; Morgan, J.; Tager-Flusberg, H.; Lainhart, J.E. Comorbid psychiatric disorders in children with autism: Interview development and rates of disorders. J. Autism Dev. Disord. 2006, 36, 849-861. [CrossRef] [PubMed]

12. Simonoff, E.; Pickles, A.; Charman, T.; Chandler, S.; Loucas, T.; Baird, G. Psychiatric disorders in children with autism spectrum disorders: Prevalence, comorbidity, and associated factors in a population-derived sample. J. Am. Acad. Child Adolesc. Psychiatry 2008, 47, 921-929. [CrossRef] [PubMed]

13. Angold, A.; Costello, E. A test-retest reliability study of child-reported psychiatric symptoms and diagnoses using the Child and Adolescent Psychiatric Assessment (CAPA-C). Psychol. Med. 1995, 25, 755-762. [CrossRef] [PubMed]

14. Rosenberg, R.E.; Kaufmann, W.E.; Law, J.K.; Law, P.A. Parent report of community psychiatric comorbid diagnoses in autism spectrum disorders. Autism Res. Treat. 2011, 2011, 10. [CrossRef] [PubMed] 
15. Kanne, S.M.; Abbacchi, A.M.; Constantino, J.N. Multi-informant ratings of psychiatric symptom severity in children with autism spectrum disorders: The importance of environmental context. J. Autism Dev. Disord. 2009, 39, 856-864. [CrossRef] [PubMed]

16. Achenbach, T.M.; Rescorla, L.A. Manual for the ASEBA Preschool Forms \& Profiles; Research Center for Children, Youth \& Families, University of Vermont: Burlington, VT, USA, 2001.

17. Achenbach, T.M.; Rescorla, L.A. Manual for the ASEBA School-Age Forms E Profiles; Research Center for Children, Youth \& Families, University of Vermont: Burlington, VT, USA, 2001.

18. Hurtig, T.; Kuusikko, S.; Mattila, M.L.; Haapsamo, H.; Ebeling, H.; Jussila, K.; Joskitt, L.; Pauls, D.; Moilanen, I. Multi-informant reports of psychiatric symptoms among high-functioning adolescents with Asperger syndrome or autism. Autism 2009, 13, 583-598. [CrossRef] [PubMed]

19. Chambers, W.J.; Puig-Antich, J.; Hirsch, M.; Paez, P.; Ambrosini, P.J.; Tabrizi, M.A.; Davies, M. The assessment of affective disorders in children and adolescents by semistructured interview. Test-retest reliability of the schedule for affective disorders and schizophrenia for school-age children, present episode version. Arch. Gen. Psychiatry 1985, 42, 696-702. [CrossRef] [PubMed]

20. Kaufman, J.; Birmaher, B.; Brent, D.; Rao, U.; Flynn, C.; Moreci, P.; Williamson, D.; Ryan, N. Schedule for affective disorders and schizophrenia for school-age children-present and lifetime version (K-SADS-PL): Initial reliability and validity data. J. Am. Acad. Child Adolesc. Psychiatry 1997, 36, 980-988. [CrossRef] [PubMed]

21. Barnhill, G.P.; Myles, B.S. Attributional style and depression in adolescents with Asperger Syndrome. J. Posit. Behav. Interv. 2001, 3, 175-182. [CrossRef]

22. Kovacs, M. Children's Depression Inventory; Multi-Health Systems: North Tonawanda, NY, USA, 1992.

23. Rai, D.; Culpin, I.; Heuvelman, H.; Magnusson, C.M.K.; Carpenter, P.; Jones, H.J.; Emond, A.M.; Zammit, S.; Golding, J.; Pearson, R.M. Association of autistic traits with depression from childhood to age 18 years. JAMA Psychiatry 2018, 75, 835-843. [CrossRef] [PubMed]

24. Angold, A.; Erkanli, A.; Silberg, J.; Eaves, L.; Costello, E.J. Depression scale scores in 8-17-year-olds: Effects of age and gender. J. Child Psychol. Psychiatry 2002, 43, 1052-1063. [CrossRef] [PubMed]

25. Kim, J.A.; Szatmari, P.; Bryson, S.E.; Streiner, D.L.; Wilson, F.J. The prevalence of anxiety and mood problems among children with autism and Asperger syndrome. Autism 2000, 4, 117-132. [CrossRef]

26. Boyle, M.H.; Offord, D.R.; Racine, Y.; Fleming, J.E.; Szatmari, P.; Sanford, M. Evaluation of the revised Ontario child health study scales. J. Child Psychol. Psychiatry 1993, 34, 189-213. [CrossRef] [PubMed]

27. Whitehouse, A.J.; Durkin, K.; Jaquet, E.; Ziatas, K. Friendship, loneliness and depression in adolescents with Asperger's syndrome. J. Adolesc. 2009, 32, 309-322. [CrossRef] [PubMed]

28. Weissman, M.M.; Orvaschel, H.; Padian, N. Children's symptom and social functioning self-report scales: Comparison of mothers' and children's reports. J. Nerv. Ment. Dis. 1980, 168, 736-740. [CrossRef] [PubMed]

29. Mazzone, L.; Postorino, V.; De Peppo, L.; Fatta, L.; Lucarelli, V.; Reale, L.; Giovagnoli, G.; Vicari, S. Mood symptoms in children and adolescents with autism spectrum disorders. Res. Dev. Disabil. 2013, 34, 3699-3708. [CrossRef] [PubMed]

30. Poznanski, E.O.; Mokros, H.B. Children's Depression Rating Scale, Revised (CDSR-R); Western Psychological Services: Los Angeles, CA, USA, 1996.

31. Brereton, A.V.; Tonge, B.J.; Einfeld, S.L. Psychopathology in children and adolescents with autism compared to young people with intellectual disability. J. Autism Dev. Disord. 2006, 36, 863-870. [CrossRef] [PubMed]

32. Einfeld, S.L.; Tonge, B.J. Manual for the Developmental Behaviour Checklist (DBC); Monash University Centre for Developmental Psychiatry and School of Psychiatry, University of NSW: Clayton, Australia; Melbourne, Australia; Sydney, Australia, 1992.

33. Enfeld, S.L.; Tonge, B.J. The Developmental Behavior Checklist: The development and validation of an instrument to assess behavioural and emotional disturbance in children and adolescents with mental retardation. J. Autism Dev. Disord. 1995, 25, 81-104. [CrossRef]

34. Green, J.; Gilchrist, A.; Burton, D.; Cox, A. Social and psychiatric functioning in adolescents with Asperger syndrome compared with conduct disorder. J. Autism Dev. Disord. 2000, 30, 279-293. [CrossRef] [PubMed]

35. Ghaziuddin, M.; Greden, J. Depression in children with autism/pervasive developmental disorders: A case-control family history study. J. Autism Dev. Disord. 1998, 28, 111-115. [CrossRef] [PubMed]

36. Piven, J.; Palmer, P. Psychiatric disorder and the broad autism phenotype: Evidence from a family study of multiple-incidence autism families. Am. J. Psychiatry 1999, 156, 557-563. [PubMed] 
37. Ghaziuddin, M.; Alessi, N.; Greden, J. Life events and depression in children with pervasive developmental disorders. J. Autism Dev. Disord. 1995, 25, 495-502. [CrossRef] [PubMed]

38. Mayes, S.D.; Calhoun, S.L.; Murray, M.J.; Zahid, J. Variables associated with anxiety and depression in children with autism. J. Dev. Phys. Disabil. 2011, 23, 325-337. [CrossRef]

39. Lindgren, S.D.; Koeppl, G.K. Assessing child behavior problems in a medical setting: Development of the Pediatric Behavior Scale. In Advances in Behavioral Assessment of Children and Families; Prinz, R.J., Ed.; JAI Press: London, UK, 1987; Volume 3, pp. 57-90.

40. Mayes, S.D.; Calhoun, S.L.; Murray, M.J.; Ahuja, M.; Smith, L.A. Anxiety, depression, and irritability in children with autism relative to other neuropsychiatric disorders and typical development. Res. Autism Spectr. Disord. 2011, 5, 474-485. [CrossRef]

41. Salazar, F.; Baird, G.; Chandler, S.; Tseng, E.; O'sullivan, T.; Howlin, P.; Pickles, A.; Simonoff, E. Co-occurring psychiatric disorders in preschool and elementary school-aged children with autism spectrum disorder. J. Autism Dev. Disord. 2015, 45, 2283-2294. [CrossRef] [PubMed]

42. Pouw, L.B.C.; Rieffe, C.; Stockmann, L.; Gadow, K.D. The link between emotion regulation, social functioning, and depression in boys with ASD. Res. Autism Spectr. Disord. 2013, 7, 549-556. [CrossRef]

43. Gray, K.; Keating, C.; Taffe, J.; Brereton, A.; Einfeld, S.; Tonge, B. Trajectory of behavior and emotional problems in autism. Am. J. Dev. Disabil. 2012, 117, 121-133. [CrossRef] [PubMed]

44. Gotham, K.; Brunwasser, S.M.; Lord, C. Depressive and anxiety symptom trajectories from school-age through young adulthood in samples with autism spectrum disorder and developmental delay. J. Am. Acad. Child Adolesc. Psychiatry 2015, 54, 369-376. [CrossRef] [PubMed]

45. Culpin, I.; Mars, B.; Pearson, R.M.; Golding, J.; Heron, J.; Bubak, I.; Carpenter, P.; Magnusson, C.; Gunnell, D.; Rai, D. Autistic traits and suicidal thoughts, plans, and self-harm in late adolescence: Population-based cohort study. J. Am. Acad. Child Adolesc. Psychiatry 2018, 57, 313-320. [CrossRef] [PubMed]

46. Baribeau, D.A.; Anagnostou, E. An update on medication management of behavioral disorders in autism. Curr. Psychiatry Rep. 2014, 16, 437. [CrossRef] [PubMed]

47. Autism Speaks. Autism Speaks Announces Results Reported for the Study of Fluoxetine in Autism (SOFIA), First Industry-Sponsored Trial for the Autism Clinical Trials Network (ACTN); Autism Speaks Inc.: New York, NY, USA, 2009.

48. King, B.H.; Hollander, E.; Sikich, L.; McCracken, J.T.; Scahill, L.; Bregman, J.D.; Donnelly, C.L.; Anagnostou, E.; Dukes, K.; Sullivan, L.; et al. Lack of efficacy of citalopram in children with autism spectrum disorders and high levels of repetitive behavior: Citalopram ineffective in children with autism. Arch. Gen. Psychiatry 2009, 66, 583-590. [CrossRef] [PubMed]

49. Owley, T.; Walton, L.; Salt, J.; Guter, S.; Winnega, M.; Lenthal, B.L.; Cook, E.H. An open-label trial of escitalopram in pervasive developmental disorders. J. Am. Acad. Child Adolesc. Psychiatry 2005, 44, 343-348. [CrossRef] [PubMed]

50. Spencer, D.; Marshall, J.; Post, B.; Kulakodiu, M.; Newschaffer, C.; Dennen, T.; Azocar, F.; Jain, A. Psychotropic medication use and polypharmacy in children with autism spectrum disorders. Pediatrics 2013, 132, 833-840. [CrossRef] [PubMed]

51. Martin, A.; Scahill, L.; Klin, A.; Volkmar, F.R. Higher-functioning pervasive developmental disorders: Rates and patterns of psychotropic drug use. J. Am. Acad. Child Adolesc. Psychiatry 1999, 38, 923-931. [CrossRef] [PubMed]

52. Esbensen, A.J.; Greenberg, J.S.; Seltzer, M.M.; Aman, M.G. A longitudinal investigation of psychotropic and non-psychotropic medication use among adolescents and adults with autism spectrum disorders. J. Autism Dev. Disord. 2009, 39, 1339-1349. [CrossRef] [PubMed]

53. Williams, K.; Brignell, A.; Randall, M.; Silove, N.; Hazell, P. Selective serotonin reuptake inhibitors (SSRIs) for autism spectrum disorders (ASD). Cochrane Database Syst. Rev. 2013, 8. [CrossRef] [PubMed]

54. Danial, J.T.; Wood, J.J. Cognitive behavioral therapy for children with autism: Review and considerations for future research. J. Dev. Behav. Pediatr. 2013, 34, 702-715. [CrossRef] [PubMed]

55. McGillivray, J.A.; Evert, H.T. Group cognitive behavioural therapy program shows potential in reducing symptoms of depression and stress among young people with ASD. J. Autism Dev. Disord. 2014, 44, 2041-2051. [CrossRef] [PubMed] 
56. Lovibond, S.; Lovibond, P. The structure of negative emotional states: Comparison of the depression anxiety stress scales (DASS) with the beck depression and anxiety inventories. Behav. Res. Ther. 1995, 33, 335-343. [CrossRef]

57. Spek, A.A.; van Ham, N.C.; Nyklicek, I. Minfulness-based therapy in adults with an autism spectrum disorder: A randomized controlled trial. Res. Dev. Disabil. 2013, 34, 246-253. [CrossRef] [PubMed]

58. Hillier, A.J.; Fish, T.; Siegel, J.H.; Beversdorf, D.Q. Social and vocational skills training reduces self-reported anxiety and depression among young adults on the autism spectrum. J. Dev. Phys. Disabil. 2011, 23, 267-276. [CrossRef]

(c) (C) 2018 by the author. Licensee MDPI, Basel, Switzerland. This article is an open access article distributed under the terms and conditions of the Creative Commons Attribution (CC BY) license (http:/ / creativecommons.org/licenses/by/4.0/). 